NISTIR 7324

\title{
Analysis Catalog for the Focus 3D \\ Telemodeling Tool
}

Arthur F. Griesser, Ph.D. 


\title{
Analysis Catalog for the Focus 3D Telemodeling Tool
}

\author{
Arthur F. Griesser, Ph.D. \\ Semiconductor Electronics Devision \\ Electronics and Electrical Engineering Laboratory
}

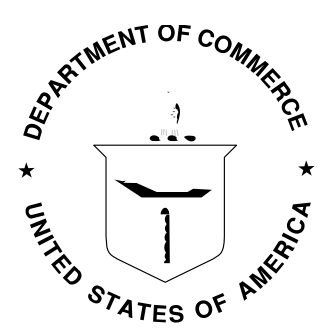

U.S. DEPARTMENT OF COMMERCE Carlos M. Gutierrez, Secretary TECHNOLOGY ADMINISTRATION Michelle O'Neill, Acting Under Secretary of Commerce for Technology NATIONAL INSTITUTE OF STANDARDS AND TECHNOLOGY 


\title{
Analysis Catalog for the Focus 3D Telemodeling Tool
}

\begin{abstract}
A high level view of the requirements for the Focus 3D modeling tool is presented. The scope of the project is defined, users of the system are described, an analysis class diagram is presented, and use cases are outlined.
\end{abstract}

\section{Table of Contents}

Overview

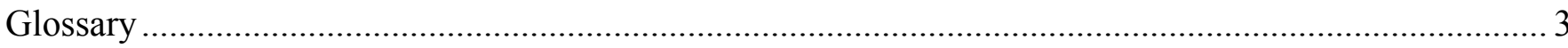

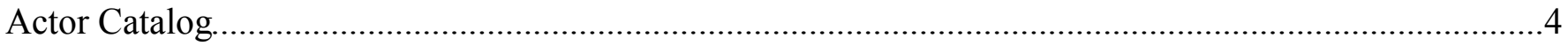



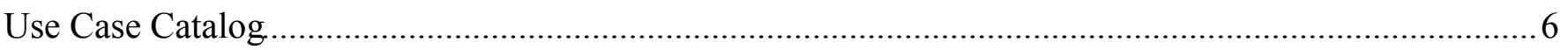

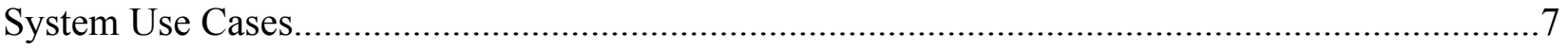

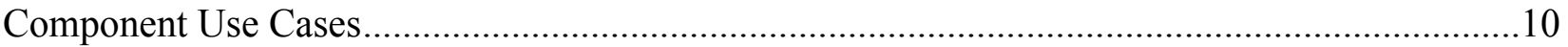

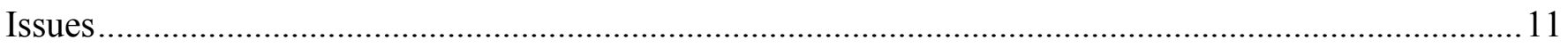

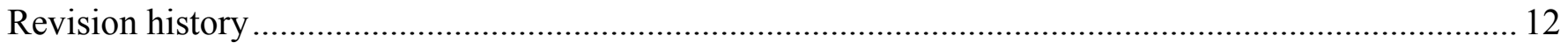

Official contribution of the National Institute of Standards and Technology; not subject to copyright in the United States. Certain commercial equipment, instruments, or materials are identified in this paper to foster understanding. Such identification does not imply recommendation or endorsement by the National Institute of Standards and Technology, nor does it imply that the materials or equipment identified are necessarily the best available for the purpose. 


\section{Overview}

The purpose of this catalog is to provide a high level view of the requirements for the Focus 3D telemodeling tool.

The goal of this project is to improve the quality of information transfer standards by providing them with underlying information models. Most standards describe in excruciating detail the format of messages. Frequently missing, however, are models of the information that's sent; even Unified Modeling Language (UML) class models (arguably the most fundamental) are often missing. Well constructed models provide a solid foundation for standards: they show and clarify all the relationships between data (not just those relationships necessary for data transmission). Models can also bridge the communication gaps between standards participants in different domains. Defects in information standards can often be traced to inadequate or missing models.

There are several reasons why standards so frequently omit class models. These models are unfamiliar to most of the volunteer domain experts participating in the standards process; it is difficult to perceive the importance of something that isn't understood. A second problem is lack of tool support for collaborative modeling. Existing modeling tools are controlled by single user. Supplemental tools such as web based desktop sharing can let other experts share the model, but this is so cumbersome as to be useless. A tool that makes it easier for domain experts to participate in collaborative modeling will result in standards with fewer ambiguities, inconsistencies, and holes.

Focus is intended make domain modeling easier by making the models less abstract and more concrete; domain classes would become three dimensional objects that resemble the instances they represent. Users could reach out and pick up a class and move it in the model, or change its properties. Multiple users could simultaneously view and manipulate the model. There are side benefits from collaborative modeling: when people work together in a shared physical space, they use gestures (such as pointing to an object) together with language that differs significantly from the language used when the people are connected only by an audio channel. In fact it has been shown that video conferencing, despite the extra layers of communication that can be conveyed by the video channel, results in language almost identical to that used in audio-only communications. Augmented reality or virtuality environments, on the other hand, result in communications similar to those used when the participants are face-to-face. Furthermore, the large muscle movements required for modeling in a virtual environment should be beneficial to "kinesthetic learners," who constitute about half the population. These factors strongly suggest that augmented environments may be more effective for collaboration than video-conferencing. Similar environments have been designed for physical modeling (of automobile dash boards, for example), but there appears to be no existing environment for domain modeling. The environment is called "Augmented Virtuality" rather than "Augmented Reality" because it is closer to the "Virtual" end of the spectrum than the "Real" end of the spectrum: the only real part of the environment will be the faces of users. 


\section{Glossary}

\begin{tabular}{|l|l|}
\hline Name & Description \\
\hline Avatar & $\begin{array}{l}\text { A virtual-world surrogate for a SystemUser. Initially Avatars will probably be cartoon- } \\
\text { like, but it would be desirable to provide them with real time expressions obtained from } \\
\text { their SystemUser. A single SystemUser may have several Avatars, selected at his or her } \\
\text { whim. }\end{array}$ \\
\hline Change & A modification of a View or Model. \\
\hline Decoration & $\begin{array}{l}\text { Wrapping behavioral delegate from the Decorator Pattern described in Design Patterns, } \\
\text { Elements of Reusable Object-Orented Software, by Gammma, Helm, Johnson, and } \\
\text { Vlissides. For example, a composition diamond is a Decoration that changes the } \\
\text { appearance of a Port. }\end{array}$ \\
\hline Layout & Spatial positioning information. \\
\hline Path & Spatial positioning information for an edge. \\
\hline Perspective & A viewpoint from which a SystemUser regards a View. \\
\hline Port & A connector that attaches an Edge to a Vertex. \\
\hline Position & $\begin{array}{l}\text { A location and orientation of shape in three dimensional space: spatial positioning } \\
\text { information for a Vertex or Port. }\end{array}$ \\
\hline Presence & $\begin{array}{l}\text { An effective user: the combination of a SystemUser, together with that user's choice of } \\
\text { Avatar and Perspective. }\end{array}$ \\
\hline Project & $\begin{array}{l}\text { Primarily a collection of models. Also a context for a modeling Session, and therefore } \\
\text { aware of the potential roles of possible SystemUsers. }\end{array}$ \\
\hline Model & $\begin{array}{l}\text { A UML-like model. Initially only a model resembling a class model, but it would be } \\
\text { desirable to eventually support 3D analogs of all UML model types. A Model by itself } \\
\text { does not include Layout information, which resides in a View. A Model may have } \\
\text { several associated views, with different levels of detail. }\end{array}$ \\
\hline Repository & A global singleton object that holds onto all persistent information. \\
\hline Session & A system use cycle. \\
\hline Stereocon & A stereoscopic icon. \\
\hline Vector & The beloved object from mathematics and physics. \\
\hline Version & $\begin{array}{l}\text { A version of a Project, capturing the complete state of all the Models composing the } \\
\text { Project. Aware of the Version from which this Version was derived. }\end{array}$ \\
\hline the same model may emphasize different aspects of the Model. \\
\hline virtual space.
\end{tabular}




\section{Actor Catalog}

\section{Hierarchy}

\begin{tabular}{|l|l|}
\hline Actor & Description \\
\hline SystemUser & Anyone who interacts with FOCUS in any way. \\
\hline Analyst & $\begin{array}{l}\text { Someone who develops analysis models, as part of the requirements definition } \\
\text { effort. Requirements usually begin as imprecise ideas that define a problem and } \\
\text { pose a solution to that problem. These ideas need to be elaborated and scrutinized } \\
\text { for consistency and clarity. }\end{array}$ \\
\hline Domain expert & $\begin{array}{l}\text { Someone with a lot of experience using the information being modeled. Domain } \\
\text { experts provide information to analysts and review the accuracy of the analysis } \\
\text { models. }\end{array}$ \\
\hline Architect & $\begin{array}{l}\text { Someone who uses analysis models to create a high level design of a solution to the } \\
\text { problem examined by the analyst. This architecture is intended to ensure that the } \\
\text { solution meets the functional and non-functional requirements articulated by the } \\
\text { analysts. }\end{array}$ \\
\hline Designer & $\begin{array}{l}\text { Someone who derives design models from the analysis models, subject to the } \\
\text { constraints of the architecture. }\end{array}$ \\
\hline Developer & Someone who implements the design models. \\
\hline Tester & $\begin{array}{l}\text { Someone who defines tests necessary to ensure that implementations produced by } \\
\text { developers actually conform to the requirements articulated by the analysts. }\end{array}$ \\
\hline SuperUser & $\begin{array}{l}\text { A SystemUser (of any type) with more modeling experience (and better familiarity } \\
\text { with FOCUS) than most. SuperUsers can become SessionManagers. When they } \\
\text { do, they acquire extra powers and responsibilities. }\end{array}$ \\
\hline SessionManager & $\begin{array}{l}\text { A role played by one SystemUser per active Session. The SessionManager initiates } \\
\text { a collaborative modeling session, controls who participates in the system, etc. This } \\
\text { role might be played by one person throughout the modeling session, or it might be } \\
\text { passed from one SystemUser to another. }\end{array}$ \\
\hline
\end{tabular}

SystemUsers can perform most operations on Models. Some operations, however, are restricted to SessionManagers, who control the session. Some operations are restricted to SuperUsers: these are more complicated, infrequently performed, or potentially dangerous. SuperUsers need to be more familiar with the tool and with modeling techniques than other SystemUsers. Modeling sessions can be held only under the supervision of a SessionManager, who is responsible for the status of the Model. A single user can therefore not modify the model alone, unless he or she is a SessionManager. This may seem restrictive compared to existing techniques of passing around documents. The idea here is to reduce gratuitous changes, and merges, and rework by requiring collaboration. 


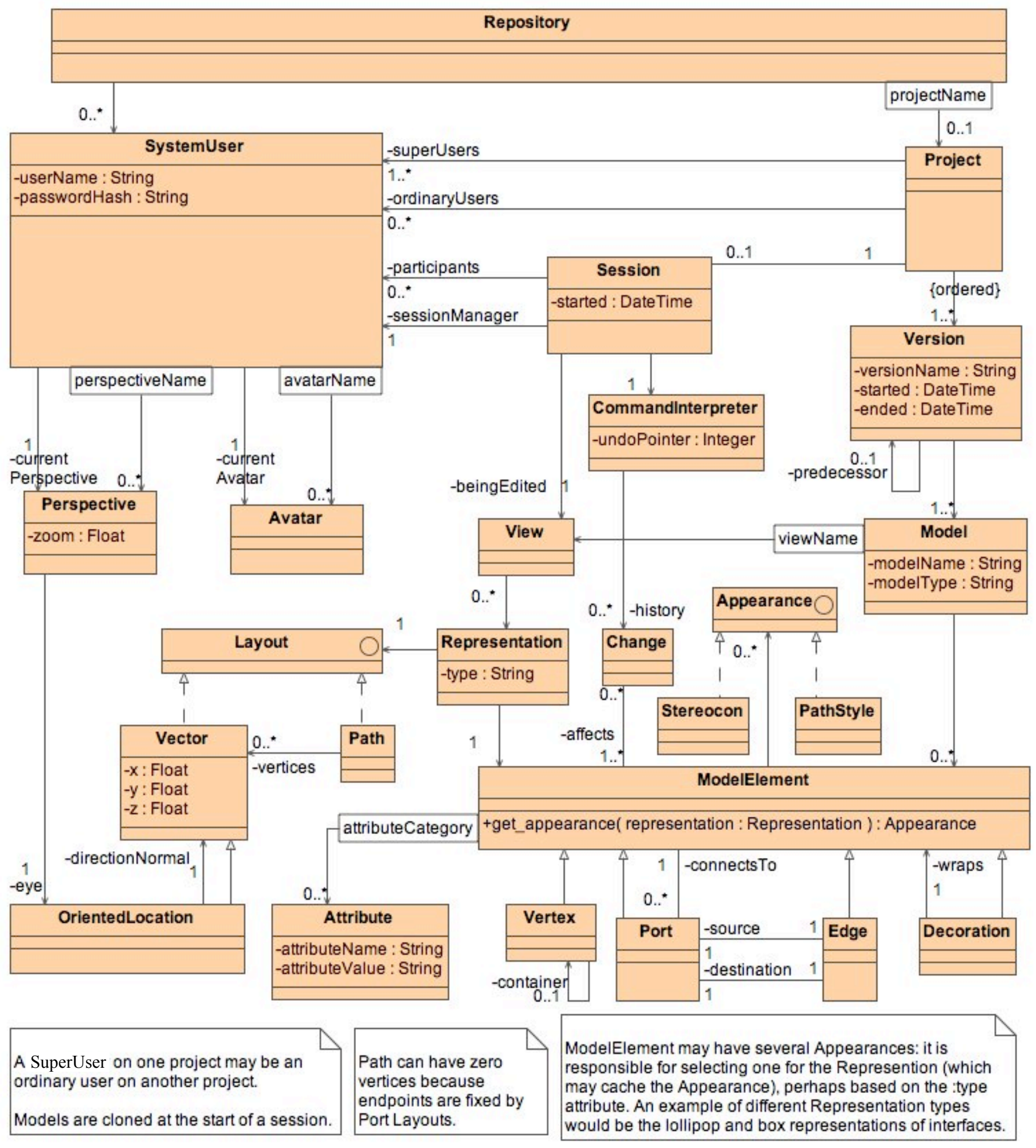




\section{Use Case Catalog}

Use cases split into "System Use Cases," which have people as Principal Actors, and "Component Use Cases" which describe internal functionality necessary for envisioned operation of the system, but which do not have human principal actors.

All of the use cases in this catalog are high-level "low granularity" use cases. Expanded low-level "high granularity" use cases (when written) are in other documents.

CRUD is an acronym standing for Create Retrieve Update Delete. Unless otherwise specified, Retrieve is expected to include both searching and browsing for the item to be retrieved.

The status column (denoted by " $s$ " in the header) contains the following values:

\begin{tabular}{|l|l|}
\hline Value & Description \\
\hline$<$ blank $>$ & Use case not yet written, but the use case is expected to be required. \\
\hline $\mathrm{C}$ & $\begin{array}{l}\text { Catalog's description appears to be sufficient; do not expect need to produce more explicit } \\
\text { use case. }\end{array}$ \\
\hline $\mathrm{N}$ & Need explicit use case, but not yet written. \\
\hline $\mathrm{P}$ & Preliminary explicit use case available, but not yet reviewed. \\
\hline $\mathrm{R}$ & Explicit use case reviewed internally. \\
\hline
\end{tabular}


System Use Cases

\begin{tabular}{|c|c|c|c|c|}
\hline $\begin{array}{l}\text { Summary } \\
\text { Goal }\end{array}$ & $\mathbf{S}$ & User Goal & Principal Actor & Description \\
\hline \multicolumn{4}{|l|}{ Session } & Control collaborative modeling sessions \\
\hline \multirow[t]{9}{*}{ Management } & C & $\begin{array}{l}\text { CRUD } \\
\text { session }\end{array}$ & SessionManager & $\begin{array}{l}\text { Session attributes include session-name, password, } \\
\text { allowed users, security options, show grid, snap to } \\
\text { grid, and minimum distance between users. }\end{array}$ \\
\hline & $\mathrm{C}$ & $\begin{array}{l}\text { Start/stop } \\
\text { session }\end{array}$ & SessionManager & $\begin{array}{l}\text { Initiate or terminate a session. SystemUsers can } \\
\text { only participate in active sessions. }\end{array}$ \\
\hline & $\mathrm{C}$ & $\begin{array}{l}\text { Handoff } \\
\text { management }\end{array}$ & SessionManager & $\begin{array}{l}\text { The SessionManager gives up this role, conferring } \\
\text { it on another SuperUser. }\end{array}$ \\
\hline & $\mathrm{C}$ & $\begin{array}{l}\text { Browse active } \\
\text { sessions }\end{array}$ & SystemUser & SystemUsers find the session they wish to join. \\
\hline & $\mathrm{C}$ & $\begin{array}{l}\text { Enter/exit } \\
\text { session }\end{array}$ & SystemUser & $\begin{array}{l}\text { SystemUsers begin or stop participating in a } \\
\text { session. }\end{array}$ \\
\hline & $\mathrm{C}$ & $\begin{array}{l}\text { Change edit } \\
\text { target }\end{array}$ & SessionManager & Specify the Model and View being edited. \\
\hline & C & $\begin{array}{l}\text { CRUD } \\
\text { Project }\end{array}$ & SessionManager & Manage information about the project. \\
\hline & $\mathrm{C}$ & CRUD Model & SessionManager & Manage information about the model. \\
\hline & $\mathrm{C}$ & CRUD View & SessionManager & $\begin{array}{l}\text { View is a way of looking at a model. It includes } \\
\text { layouts of ModelElements. Some views might be } \\
\text { constrained to 2D. }\end{array}$ \\
\hline
\end{tabular}




\begin{tabular}{|c|c|c|c|c|}
\hline \multirow[t]{15}{*}{ Edit Model } & & & & $\begin{array}{l}\text { Changes to the currently active Project, Model, and } \\
\text { View. }\end{array}$ \\
\hline & $\mathrm{N}$ & $\begin{array}{l}\text { Browse } \\
\text { ModelElements }\end{array}$ & SystemUser & $\begin{array}{l}\text { View a sorted table of ModelElements. ModelElements } \\
\text { selected in this table are also selected in the model (and } \\
\text { vice-versa). }\end{array}$ \\
\hline & $\mathrm{N}$ & $\begin{array}{l}\text { Perspective } \\
\text { modification }\end{array}$ & SystemUser & $\begin{array}{l}\text { Each SystemUser can individually zoom, translate } \\
\text { (move), and rotate the View. This is actually a change } \\
\text { in the Perspective in use. This use case is different from } \\
\text { the R in CRUD Perspective (which lets the SystemUser } \\
\text { jump to some other predefined Perspective). }\end{array}$ \\
\hline & $\mathrm{R}$ & $\begin{array}{l}\text { CRUD } \\
\text { ModelElements }\end{array}$ & SystemUser & $\begin{array}{l}\text { Expect C,D to be accomplished by gestures. R=Search } \\
\text { for model element (by name or attributes). }\end{array}$ \\
\hline & $\mathrm{R}$ & $\begin{array}{l}\text { Layout } \\
\text { Representations }\end{array}$ & SystemUser & $\begin{array}{l}\text { Change the position of Stereocons, the position on the } \\
\text { Stereocon that the edge is attached to, and the routing of } \\
\text { edges. }\end{array}$ \\
\hline & $\mathrm{N}$ & $\begin{array}{l}\text { CRUD } \\
\text { Stereotype }\end{array}$ & SuperUser & $\begin{array}{l}\text { Includes rules that determine the appearance of } \\
\text { ModelElements (taking Stereotypes into account). }\end{array}$ \\
\hline & & $\begin{array}{l}\text { Assign } \\
\text { Stereotype }\end{array}$ & SystemUser & $\begin{array}{l}\text { The ModelElement's appearance may change when the } \\
\text { Sterotype is assigned. }\end{array}$ \\
\hline & & CRUD Stereocon & SystemUser & Stereocon is $3 \mathrm{D}$ icon representing vertex. \\
\hline & $\mathrm{R}$ & $\begin{array}{l}\text { Select } \\
\text { Representation }\end{array}$ & SystemUser & Presumably by grasping. \\
\hline & $\mathrm{N}$ & $\begin{array}{l}\text { Supress/Show } \\
\text { detail }\end{array}$ & SystemUser & $\begin{array}{l}\text { Details can be hidden to provide a higher level view, or } \\
\text { to make it easier for the user to focus on some other } \\
\text { detail. }\end{array}$ \\
\hline & $\mathrm{N}$ & Undo/Redo & SystemUser & $\begin{array}{l}\text { Undo or redo any changes made during the current } \\
\text { session. Candidate changes can be selected from a list. } \\
\text { Multiple changes can be chosen at one time. The system } \\
\text { knows which changes can and cannot commute, and } \\
\text { allows only compatible sets of changes. }\end{array}$ \\
\hline & $\mathrm{N}$ & $\begin{array}{l}\text { Automatically } \\
\text { layout } \\
\text { ModelElements }\end{array}$ & SuperUser & $\begin{array}{l}\text { This is available only to the SessionManager because of } \\
\text { the large number of Changes it produces. }\end{array}$ \\
\hline & $\mathrm{N}$ & Rollback & SuperUser & $\begin{array}{l}\text { Revert the current Project, Model, View, or } \\
\text { ModelElement to its state at the end of some other } \\
\text { Session. }\end{array}$ \\
\hline & & Get help & SystemUser & $\begin{array}{l}\text { Includes search on help text, as well as hints specific to } \\
\text { nearby objects. }\end{array}$ \\
\hline & & Refactor & SystemUser & $\begin{array}{l}\text { Reorganize the model by changing the Vertex that an } \\
\text { Edge is attached to, the parent that contains a model } \\
\text { element (such as the Package that a Class belongs to, } \\
\text { the SuperState of a State), etc. }\end{array}$ \\
\hline
\end{tabular}




\begin{tabular}{|c|c|c|c|c|}
\hline \multirow[t]{7}{*}{$\mathrm{I} / \mathrm{O}$} & & & & Generate or consume related information. \\
\hline & $\mathrm{N}$ & $\begin{array}{l}\text { Generate } \\
\text { report }\end{array}$ & SystemUser & $\begin{array}{l}\text { Report on metrics such as complexity, problems } \\
\text { with the model (such as containment cycles), effort } \\
\text { to implement, etc. }\end{array}$ \\
\hline & $\mathrm{N}$ & Generate code & SystemUser & $\begin{array}{l}\text { Use templating system to support multiple } \\
\text { computer languages. Code should include XML } \\
\text { Schemas as well as executable code. }\end{array}$ \\
\hline & $\mathrm{N}$ & $\begin{array}{l}\text { Reverse } \\
\text { engineer code }\end{array}$ & SuperUser & $\begin{array}{l}\text { Automatically build and layout models that will } \\
\text { recreate the input code when "Generate code" is } \\
\text { invoked. }\end{array}$ \\
\hline & & Print & SystemUser & $\begin{array}{l}\text { Print a View of the Model as seen from the } \\
\text { requesting user's Perspective }\end{array}$ \\
\hline & $\mathrm{N}$ & Export & SystemUser & $\begin{array}{l}\text { Export Project, Model, or ModelElement to some } \\
\text { other format, such as XML Metadata Interchange } \\
\text { (XMI). }\end{array}$ \\
\hline & $\mathrm{N}$ & Import & SuperUser & $\begin{array}{l}\text { Import a Project, Model, or a fragment from some } \\
\text { other format, such as XMI. }\end{array}$ \\
\hline \multirow{3}{*}{$\begin{array}{l}\text { User } \\
\text { Preferences }\end{array}$} & & & & User maintains his or her unique options. \\
\hline & & $\begin{array}{l}\text { CRUD } \\
\text { Perspective }\end{array}$ & SystemUser & $\begin{array}{l}\text { Includes Zoom, translate (move), and rotate. R } \\
\text { includes switching to a saved Perspective and } \\
\text { browsing Perspectives: the model is shown (from } \\
\text { some default perspective), with Perspectives } \\
\text { represented by Vectors. Can show perspectives in } \\
\text { use by other SystemUsers. Can only switch to a } \\
\text { Perspective that is not too close to a perspective in } \\
\text { use by another SystemUser, or within the model. } \\
\text { These constraints are present in the physical world } \\
\text { and easily implemented through cylindrical } \\
\text { approximations. They prevent, for example, a } \\
\text { perspective inside the head of a different Avatar. } \\
\text { This is not intended to prevent a user from } \\
\text { borrowing the Perspective of another. When this is } \\
\text { done, the Avatar of the borrower should be } \\
\text { modified (for example, it might become } \\
\text { transparent) to indicate she is "out of body." The } \\
\text { Avatar of the lender should be modified as well. }\end{array}$ \\
\hline & & CRUD Avatar & SystemUser & $\begin{array}{l}\text { SystemUser can adjust the appearance of his own } \\
\text { Avatar and can also override the appearance of the } \\
\text { Avatars of the other users. }\end{array}$ \\
\hline
\end{tabular}




\section{Component Use Cases}

\begin{tabular}{|c|c|c|c|}
\hline $\begin{array}{l}\text { Summary } \\
\text { Goal }\end{array}$ & $\mathbf{S}$ & User Goal & Description \\
\hline \multicolumn{3}{|l|}{ Virtuality } & $\begin{array}{l}\text { To the SystemUser, ModelElements appear to exist as tangible } \\
\text { three dimensional objects. }\end{array}$ \\
\hline & C & Head tracking & $\begin{array}{l}\text { The system needs to know the SystemUser's head position in } \\
\text { order to compute the video to feed into the head mounted display. }\end{array}$ \\
\hline & C & Hand tacking & $\begin{array}{l}\text { The system needs to know the SytemUser's hand position to } \\
\text { determine which objects the user is intending to manipulate and to } \\
\text { determine the avatar's hand position. }\end{array}$ \\
\hline & $\mathrm{C}$ & Projection & $\begin{array}{l}\text { The current View is projected on to the SystemUser's Perspective } \\
\text { to obtain video to feed into a headmounted display. }\end{array}$ \\
\hline \multicolumn{3}{|l|}{ Reality } & Aspects of the physical world are present in modeling space. \\
\hline & & Facial video & $\begin{array}{l}\text { Video of each SystemUser's face is superimposed on that } \\
\text { SystemUser's Avatar. }\end{array}$ \\
\hline & & $\begin{array}{l}\text { Environmental } \\
\text { video }\end{array}$ & $\begin{array}{l}\text { ModelElements may appear to be superimposed upon each } \\
\text { SystemUser's phyical space. }\end{array}$ \\
\hline \multicolumn{3}{|l|}{ Collaboration } & $\begin{array}{l}\text { Multiple SystemUsers collaborate to construct and improve the } \\
\text { Model. }\end{array}$ \\
\hline & C & $\begin{array}{l}\text { Change } \\
\text { distribution }\end{array}$ & $\begin{array}{l}\text { When one SystemUser makes a change to the model, the change } \\
\text { needs to be distributed to other SystemUsers participating in this } \\
\text { session. Changes to the SystemUser's Perspective and video of } \\
\text { the user's face are also distributed so that the user's Avatar can be } \\
\text { updated. }\end{array}$ \\
\hline & $\mathrm{C}$ & Scene update & $\begin{array}{l}\text { Each SystemUser's Scene must be updated with changes } \\
\text { distributed by other other users and with changes to the Avatars of } \\
\text { the other users. }\end{array}$ \\
\hline \multirow{3}{*}{\multicolumn{2}{|c|}{$\begin{array}{l}\text { Object } \\
\text { Management }\end{array}$}} & & Control over persistent objects. \\
\hline & & Authenticate user & $\begin{array}{l}\text { Verify the identity of users logging onto the system: associate the } \\
\text { user with the appropriate SystemUser object. }\end{array}$ \\
\hline & & Abstract CRUD & Generalized persistence services. \\
\hline
\end{tabular}




\section{Issues}

\begin{tabular}{|c|c|c|c|}
\hline Name & \multicolumn{2}{|l|}{ Description } & Resolution \\
\hline \multirow[t]{8}{*}{$2 \mathrm{D}>3 \mathrm{D}$} & \multicolumn{2}{|c|}{$\begin{array}{l}\text { Some aspects of UML are } 2 \mathrm{D} \text { specific. It is not } \\
\text { immediately obvious how to represent this information in } \\
\text { 3D. }\end{array}$} & \\
\hline & Problem & Possible solutions & \\
\hline & $\begin{array}{l}\text { Class Attributes, } \\
\text { Operations }\end{array}$ & $\begin{array}{l}\text { Pop-up cluster surrounding } \\
\text { the stereocon, or popup } \\
\text { table. }\end{array}$ & \\
\hline & $\begin{array}{l}\text { Arrowheads, Composition, } \\
\text { Aggregation, Qualifier, } \\
\text { multiplicity, labels }\end{array}$ & $\begin{array}{l}\text { Same as 2D UML, but } \\
\text { different for each user, or } \\
\text { use new 3D representations } \\
\text { (perhaps derived from Entity } \\
\text { Relation Diagram [ERD] } \\
\text { multiplicity representations). }\end{array}$ & \\
\hline & Notes & $\begin{array}{l}\text { Stereocon (notebook?) that } \\
\text { expands to 2D note. }\end{array}$ & \\
\hline & $\begin{array}{l}\text { Distinguish a class from } \\
\text { instance }\end{array}$ & $\begin{array}{l}\text { Perhaps by size, brightness, } \\
\text { internal illumination, } \\
\text { transparency, color, texture, } \\
\text { aura, halo, crown, elevation. }\end{array}$ & \\
\hline & $\begin{array}{l}\text { Abstract domain objects } \\
\text { (not clear what 3D shape } \\
\text { should be used) }\end{array}$ & $\begin{array}{l}\text { Morph together the concrete } \\
\text { classes Stereocons? Reserve } \\
\text { a Stereocon (an amorphous } \\
\text { blob?) for abstract classes. } \\
\text { Of course this could be } \\
\text { overridden. }\end{array}$ & \\
\hline & Nested states & Translucent outer states & \\
\hline Stereocon name & \multicolumn{2}{|c|}{ There must be some better name for "stereocon." } & \\
\hline $\begin{array}{l}\text { Stereocon } \\
\text { definition }\end{array}$ & \multicolumn{2}{|c|}{$\begin{array}{l}\text { It would be disruptive to have to create a new stereocon } \\
\text { for each class. Perhaps use a simple geometric object } \\
\text { until users decide on a representation. }\end{array}$} & \\
\hline Update & \multicolumn{2}{|c|}{$\begin{array}{l}\text { The brief descriptions in version } 0.3 \text { need to be updated } \\
\text { for those use cases that now have complete definitions. }\end{array}$} & \\
\hline
\end{tabular}




\section{Revision history}

(last entry applies to the current document)

\begin{tabular}{|c|c|c|c|}
\hline Version & Date & Developer & Change \\
\hline 0.1 & $12 / 30 / 04$ & $\mathrm{AFG}$ & First cut \\
\hline 0.2 & $1 / 5 / 05$ & AFG & $\begin{array}{l}\text { - Changed name from AVUML to Focus. } \\
\text { - Corrected scope names. } \\
\text { - Expanded Glossary definition of Decoration. } \\
\text { - Rejected request that SuperUser not be more experienced with } \\
\text { modeling and/or Focus. SuperUser is defined by extra powers, } \\
\text { which require extra knowledge. } \\
\text { - Accepted request that SessionManager not require more modeling } \\
\text { experience than SuperUser. Changed Actor from SessionManager } \\
\text { to SuperUser for: CRUD_Stereotype, } \\
\text { Automatically_Layout_ModelElements, Rollback, I/ } \\
\text { O:Reverse_engineer_code, I/O:Import (all user goals within } \\
\text { summary goal, unless otherwise indicated). } \\
\text { - Rejected request to drop distinction between icon and stereocon } \\
\text { (icons look 3D, but are actually planar, such as some Croquet } \\
\text { icons, whereas stereocons actually are 3D and have underlying } \\
\text { 3D models). The program needs to handle these differently. } \\
\text { - Rejected request to add 5-change block-undo bookmark. } \\
\text { - Added list of undo/redo candidates, knowledge of change } \\
\text { commutativity. } \\
\text { - Clarify EditModel.Refactor (more details will be added to full use } \\
\text { case). }\end{array}$ \\
\hline
\end{tabular}




\begin{tabular}{|c|c|c|c|}
\hline 0.3 & $8 / 26 / 05$ & AFG & 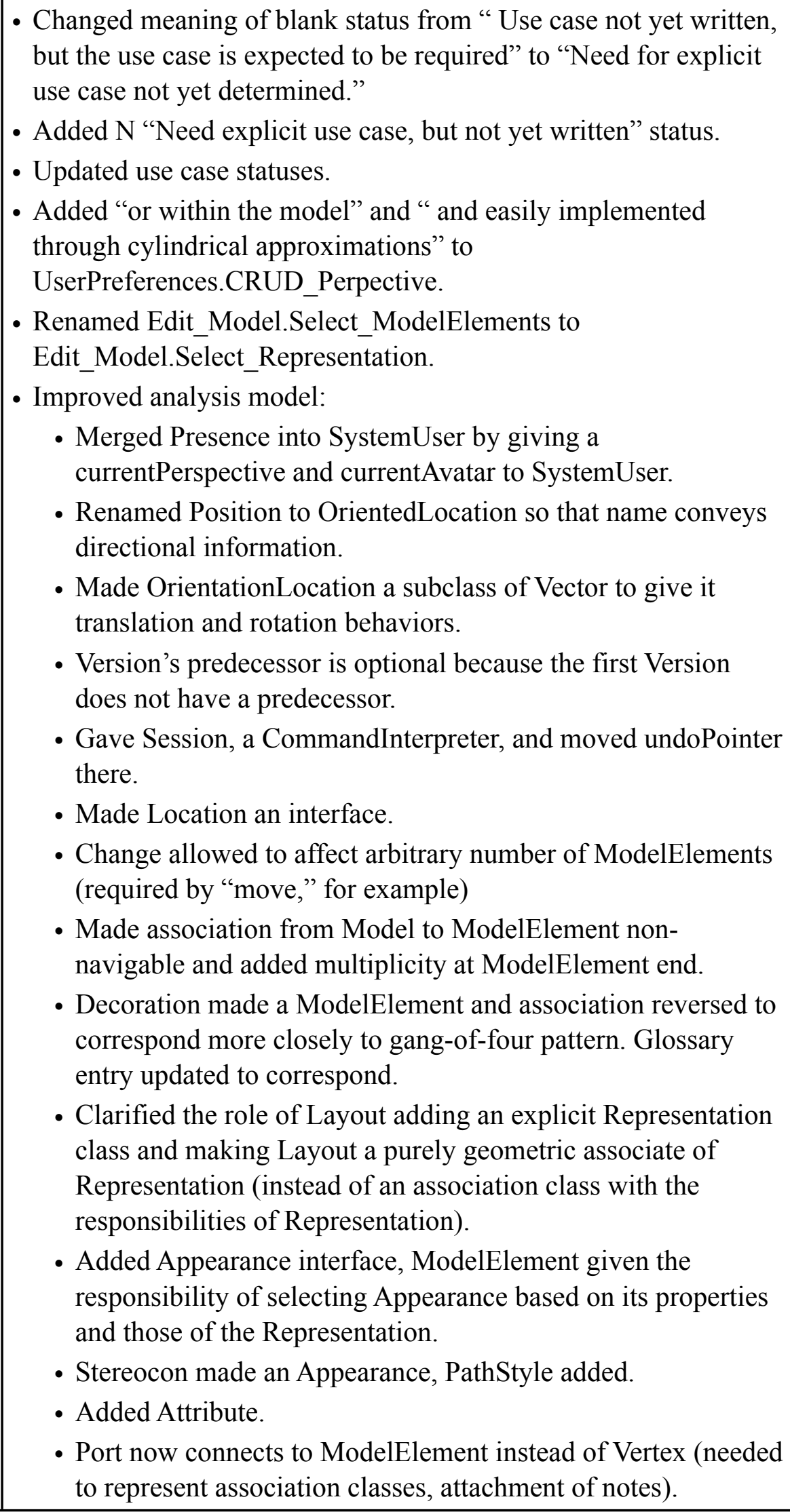 \\
\hline
\end{tabular}

